\title{
DESENVOLVIMENTO DE UMA BEBIDA SEMELHANTE AO ALUÁ, COM FERMENTAÇÃO CONTROLADA, UTILIZANDO BACTÉRIAS LÁTICAS ISOLADAS DA FERMENTAÇÃO ESPONTÂNEA DA CASCA DO ABACAXI.
}

\author{
Amanda Pereira Texeira ${ }^{1}$; Elinalva Maciel Paulo e Ilana Maciel Paulo Mamédio ${ }^{3}$ \\ ${ }_{1}$ Bolsista PIBIT/CNPq, Graduanda do curso de Engenharia de Alimentos, Universidade Estadual de Feira de Santana, email: \\ amandatexeira28@hotmail.com \\ 2 Orientadora: Docente do Departamento de Ciências Biológicas, Universidade Estadual de Feira de Santana, email: \\ elinalvamaciel@yahoo.com.br \\ ${ }_{3}$ Co-orientadora: Departamento de Ciências Biológicas, Universidade Estadual de Feira de Santana, email: \\ ilana_mamedio@hotmail.com
}

PALAVRAS-CHAVE: Bactérias láticas; Ananas comosus; Aluá.

\section{INTRODUÇÃO}

As bactérias láticas (BAL) pertencem a um grupo de bactérias que têm como principal produto metabólico o ácido lático. Estas bactérias possuem distribuição vasta na natureza, podendo ser encontradas em superfície de plantas, no trato digestório e genital dos animais, no leite, etc. A maioria das espécies pertencente a este grupo não são patogênicas, por isso são utilizadas na elaboração e obtenção de diversos produtos (PAULO, 2010).

Muitos destes produtos são elaborados pelo processo da fermentação e um exemplo típico de fermentação espontânea é o aluá. Essa é uma bebida refrigerante e de origem indígena que muda-se o ingrediente principal dependendo da região em que é consumida. No Acre e no resto da Amazônia é comum se usar o milho triturado ou a farinha de milho. Em outras regiões, como por exemplo, em Belém, se usam cascas de frutas como o abacaxi, raiz de gengibre (também conhecido regionalmente por Mangarataia) (esmagada ou ralada), açúcar ou caldo de cana e sumo de limão. Na cidade de Manaus e arredores, são usadas as cascas de abacaxi (postas de molho na água, por três dias, juntas às raízes de mangarataia (gengibre)) e milho, depois, adiciona-se açúcar, cravinho e erva-doce. Ferve-se, deixa-se esfriar e depois gelar (WIKIPÉDIA, 2015).

A utilização da casca do abacaxi, que normalmente é devolvida ao ambiente como resíduo sem aproveitamento algum, constitui um excelente substrato para a elaboração de uma bebida fermentada de propriedade funcional. A utilização de culturas láticas starter, isoladas da própria planta (abacaxi) para a elaboração de uma bebida fermentada, com processo controlado e padronizado será de grande importância para o aprimoramento de uma bebida regional de grande promoção à saúde dos consumidores.

\section{MATERIAIS E MÉTODOS}

Foram utilizadas amostras de cascas de abacaxi que foram submetidas ao processo de fermentação baseado em experimentos realizados por Grizotto e Menezes (2004) para isolamento das BAL. A amostra foi coletada em feira-livre localizada na cidade de Feira de Santana-BA, onde os procedimentos de coleta e transporte da amostra foram realizados de forma asséptica. O isolamento das BAL procedeu-se de acordo com PAULO (2010) utilizando o meio ágar MRS (DE MAN; ROGOSA; SHARPE, 1960) sendo realizados primeiramente o teste de coloração de Gram e o teste da catalase (KONEMAN, 2008).

Em seguida, realizaram-se alguns testes em duplicata de caracterização bioquímica dos isolados: produção de gás a partir da glicose; lactofermentação a $15^{\circ} \mathrm{C}, 35^{\circ} \mathrm{C}$ e $45^{\circ} \mathrm{C}$; tolerância bacteriana ao $\mathrm{NaCl}$ em diferentes concentrações (4\%, 6\% e 8\%); redução do nitrato a nitrito; produção de amônia a partir do caldo descarboxila de lisina; fermentação de diferentes carboidratos (CHAVES, 1999) pelo Sistema API 50CHL (Bio-Mérieux); VogesProskauer. 
Foram preparadas 8 bebidas com a cultura starter ( 2 bactérias láticas ativadas isoladas do aluá e mais 1 pertencente à bacterioteca do Laboratório de Microbiologia Aplicada à Saúde Pública (LAMASP/UEFS)) e 1 com fermentação espontânea. Após cada incubação fez-se a determinação de parâmetros físico-químicos: $\mathrm{pH}$, teor alcoólico e açúcar redutor total (BRASIL, 2005).

\section{RESULTADOS E/OU DISCUSSÃO}

Foram obtidos 16 isolados da fermentação espontânea. Os isolados que apresentaram morfologia de bastonetes, Gram positivos, catalase negativa e não redutores de nitrato a nitrito foram considerados preliminarmente como pertencentes ao grupo das bactérias láticas (PAULO, 2010). A partir daí 3 isolados foram escolhidos para serem identificados e caracterizados.

Nenhum dos isolados produziu gás a partir da glicose sendo considerados homofermentativos de acordo com os critérios de CHAVES (1999). No teste de lactofermentação (Tabela1) ocorreu $100 \%$ de crescimento a $35^{\circ} \mathrm{C}$, mas a formação de coágulo firme foi para apenas 1 dos isolados ( $\mathrm{ABX} 3$ ), à $15^{\circ} \mathrm{C}$ este crescimento foi de $33,3 \%$ e à $45^{\circ} \mathrm{C}$ não houve crescimento. As bactérias $\mathrm{ABX} 4.1$ e $\mathrm{ABX} 5.2$ foram consideradas bactérias mesófilas, já a ABX 3 foi considerada psicodúrica.

Tabela 1. Apresentação de coagulação do meio LDR 10\% em diferentes temperaturas (* formação de coágulo pouco estruturado).

\begin{tabular}{l|l|l|l}
\hline Isolado & $\mathbf{1 5}^{\circ} \mathbf{C}$ & $\mathbf{3 5}^{\circ} \mathbf{C}$ & $\mathbf{4 5}^{\circ} \mathbf{C}$ \\
\hline ABX 3 & Positivo & Positivo & Negativo \\
\hline ABX4.1 & Negativo & Positivo* & Negativo \\
\hline ABX 5.2 & Negativo & Positivo* $^{*}$ & Negativo \\
\hline
\end{tabular}

Foram observadas algumas características importantes para identificação dessas bactérias, estas características referem-se ao aspecto do meio LDR 10\% após o crescimento delas, características, como formação de soro (100\% dos resultados positivos) e aspecto do coágulo que influencia na escolha da linhagem que deverá ser utilizada na elaboração de produtos lácteos fermentados.

Tabela 2. Teste de halotolerância em diferentes concentrações de $\mathrm{NaCl}$ (+ pouco crescimento; ++ bom crescimento; +++ ótimo crescimento).

\begin{tabular}{l|l|l|l}
\hline Isolado & $\mathbf{4 \%}$ & $\mathbf{6 \%}$ & $\mathbf{8 \%}$ \\
\hline ABX 3 & Positivo+++ & Positivo+ & Negativo \\
\hline ABX4.1 & Positivo+++ & Positivo++ & Negativo \\
\hline ABX 5.2 & Positivo+++ & Positivo++ & Negativo \\
\hline
\end{tabular}

O teste de tolerância bacteriana ao cloreto de sódio $(\mathrm{NaCl})$ demonstrou que todos os isolados cresceram a $4 \%$ e a $6 \%$, mas nenhum cresceu a $8 \%$ (Tabela 2). Caso crescessem em todas as concentrações poderiam, segundo POFFO (2011), serem consideradas halófilicas, pois as taxas de crescimento de algumas bactérias tendem a aumentar com o aumento da concentração salina. No teste de redução do nitrato e produção da amônia pelo caldo descarboxila de lisina, houve 100\% de resultados negativos. Já para o Voges-Proskauer apenas ABX 3 apresentou formação de diacetil.

Para a fermentação de diferentes carboidratos foi utilizado o sistema API 50CHL (BioMérieux), sua leitura forneceu a identificação fenotípica das bactérias e sua porcentagem de identificação: Lactobacillus plantarum (ABX 3 - 99,4\% ID e ABX 4.1 - 99,9\% ID) e Lactobacillus paracasei ssp. paracasei 1 (ABX 5.2 - 99,7\% ID) ambas são bactérias com 
propriedades probióticas (ÁVILA, 2007) podendo ser utilizadas na bebida fermentada deste projeto.

As bebidas fermentadas feitas foram 9 no total: $4 \mathrm{com}$ as bactérias isoladas do Aluá (ABX 3 e ABX 5.2), 2 com um isolado pertencente à bacterioteca do LAMASP/UEFS (U205 - Lactobacillus plantarum), 2 com cultura mista (ABX 3 + ABX 5.2 + U205) e 1 com fermentação espontânea.

Em relação às análises físico-químicas das bebidas produzidas observando a Tabela 3, tem-se em todos os períodos de fermentação uma grande redução do $\mathrm{pH}$, sendo que na temperatura de $35^{\circ} \mathrm{C}$ esta redução é mais drástica, o que torna o produto impalatável pelo excesso de produção de ácido lático. Mas quando fermentado a $6^{\circ} \mathrm{C}$ ocorre uma menor produção de ácido lático, resultado parecido com o aluá produzido de forma artesanal. Os pHs obtidos são suportáveis para as bactérias láticas, característica que as capacita a eliminar a competição da maioria das bactérias em ambientes ricos em nutrientes (TORO, 2005; BERNARDEAU et. al, 2008). Em relação ao teor alcoólico, a bebida fermentada pela cultura mista a $35^{\circ} \mathrm{C} / 48 \mathrm{~h}$ e a bebida da cultura espontânea obtiveram um maior valor deste parâmetro e um menor valor de ${ }^{\circ}$ Brix, comparados aos outros ensaios deste trabalho, inferindo que quando o aluá é produzido com mais de uma espécie de micro-organismo ocorre maior produção de álcool. Apesar das linhagens isoladas serem homofermentativas no caldo MRS, elas mostraram-se como heterofermentativa, pois produziram além de ácido lático o álcool. Isto é possível de acontecer se elas forem heterofermentativas facultativas.

A proporção de sacarose acrescentada para a elaboração do aluá, foi de $8,34 \%$. Pode observar pela Tabela 3 que os experimentos que ocorreram maior detecção de açúcar redutor em glicose foram os aluás elaborados pela fermentação espontânea a $6^{\circ} \mathrm{C}$ por 15 dias e pela cultura mista $35^{\circ} \mathrm{C}$ por $48 \mathrm{~h}$, indicando onde houve maior conversão da sacarose em glicose pelo processo da fermentação, mas também indicando o consumo da glicose pelos microorganismos, uma vez que se este açúcar não fosse consumido, a concentração de glicose seria bem maior do que o apresentado na tabela.

Tabela 3. Parâmetros físico-químicos das bebidas fermentadas em cada período de incubação.

\begin{tabular}{|c|c|c|c|}
\hline $\begin{array}{l}\text { Isolado / Tempo de } \\
\text { Incubação }\end{array}$ & pH & $\begin{array}{l}\text { Teor Alcoólico (Alcohol } \\
\text { By Volume (\%)) }\end{array}$ & $\begin{array}{l}\text { Açúcar Redutor } \\
\text { em glicose } \%\end{array}$ \\
\hline $\begin{array}{l}\text { Lactobacillus plantarum } \\
\mathrm{ABX} 3 / 35^{\circ} \mathrm{C} \text { por } 48 \mathrm{~h}\end{array}$ & 3,05 & 0,00 & 1,40 \\
\hline $\begin{array}{l}\text { Lactobacillus paracasei } \\
\text { ssp. paracasei } 1 \mathrm{ABX} 5.2 \\
/ 35^{\circ} \mathrm{C} \text { por } 48 \mathrm{~h}\end{array}$ & 2,87 & 0,96 & 1,66 \\
\hline $\begin{array}{l}\text { Lactobacillus plantarum } \\
\mathrm{U} 205 / 35^{\circ} \mathrm{C} \text { por } 48 \mathrm{~h}\end{array}$ & 2,76 & 3,36 & 1,16 \\
\hline $\begin{array}{l}\text { Cultura mista/ } 35^{\circ} \mathrm{C} \text { por } \\
48 \mathrm{~h}\end{array}$ & 2,67 & 4,13 & 2,14 \\
\hline $\begin{array}{l}\text { Lactobacillus plantarum } \\
\mathrm{ABX} 3 / 6^{\circ} \mathrm{C} \text { por } 1 \text { mês }\end{array}$ & 4,00 & 0,00 & 0,81 \\
\hline $\begin{array}{l}\text { Lactobacillus paracasei } \\
\text { ssp. paracasei } 1 \mathrm{ABX} 5.2 \\
\text { / } 6^{\circ} \mathrm{C} \text { por } 1 \text { mês }\end{array}$ & 3,99 & 0,00 & 1,04 \\
\hline $\begin{array}{l}\text { Espontâneo / } 6^{\circ} \mathrm{C} \text { por } 1 \\
\text { mês }\end{array}$ & 4,00 & 3,37 & 2,00 \\
\hline $\begin{array}{l}\text { Lactobacillus plantarum } \\
\mathrm{U} 205 / 6^{\circ} \mathrm{C} \text { por } 15 \text { dias }\end{array}$ & 3,66 & 0,12 & 0,47 \\
\hline
\end{tabular}




\begin{tabular}{l|c|c|c}
\hline $\begin{array}{l}\text { Cultura mista } / 6^{\circ} \mathrm{C} \text { por } \\
15 \text { dias }\end{array}$ & 3,71 & 0,12 & 0,57 \\
\hline
\end{tabular}

\section{CONCLUSÃO}

A partir da fermentação espontânea da casca do abacaxi (aluá) é possível obter bactérias com características probióticas e de boa capacidade de crescimento durante a fermentação como o Lactobacillus plantarum e o Lactobacillus paracasei ssp. paracasei 1 e produzir o aluá através da fermentação controlada com micro-organismos específicos, obtendo parâmetros físico-químicos desejáveis. Sendo assim é possível transformar o aluá produzido de forma artesanal, em uma bebida com padrões de identificação de qualidade e possivelmente com características organolépticas apreciáveis pelo consumidor e, portanto, passível de ser industrializado.

\section{REFERÊNCIAS}

ÁVILA, C. L. S. Isolamento e uso de Lactobacillus buchneri na ensilagem de capimmombaça e cana-de-açúcar. 2007. 175f. Tese (Doutorado em Zootecnia) - Universidade Federal de Lavras, Lavras, 2007.

BRASIL. Ministério da Saúde. Agência Nacional de Vigilância Sanitária. Métodos Físicoquímicos para Análise de Alimentos. 4. ed. Brasília: Ministério da Saúde, 2005. p.1018.

CHAVES, A. H. et al. Isolamento de Lactobacillus acidophilus a Partir de Fezes de Bezerros. Rev. bras. zootec., v.28,n.5, p.1086-1092, 1999.

DE MAN, J.C.; ROGOSA, M.; SHARPE, M.E. A medium for cultivation of lactobacilli. $J$. Appl. Bacteriol. v. 23, p.130-135, 1960.

GRIZZOTO, R. K.; MENEZES, H.C. Efeito da fermentação na qualidade de "chips" de mandioca (Manihot esculenta Crantz). Ciência e Tecnologia de Alimentos, v.24, n.2, p.170177, abr.-jun.2004.

KONEMAN, E.W.; ALLEN, S.D.; JANDA. et al. Diagnóstico Microbiológico: texto e atlas colorido. 6.ed. Rio de Janeiro: Guanabara, 2008. p.1600.

PAULO, E. P. Produção de exopolissacarídeos (EPS) por bactérias láticas visando microencapsulação de Lactobacillus acidophilus La-5 pelo processo de Spray drying. 2010. Tese 212f. (Doutorado em Biotecnologia), Departamento de Ciências Biológicas, Universidade Estadual de Feira de Santana, Feira de Santana, 2010.

POFFO, F.; SILVA, M. A. C. Caracterização taxonômica e fisiológica de bactérias ácidoláticas isoladas de pescado marinho. 2011. Disponível em: <http://www.scielo.br/pdf/cta/v31n2/v31n2a04>. Acesso em: 12 maio 2015.

TORO, C. R. Uso de bactérias lácticas probióticas na alimentação de camarões Litopenaeus vannamei como inibidoras de microrganismos patogênicos e estimulantes do sistema imune. 2005. 153 f. Tese (Doutorado em Processos Biotecnológicos) - Universidade Federal do Paraná, Curitiba, 2005.

WIKIPÉDIA. Aluá. 2015. Disponível em: < http://pt.wikipedia.org/wiki/Alu\%C3\%A1>. Acesso em: 26 maio. 2015. 